\title{
OUTCOMES OF SURGICAL MANAGEMENT OF DISTAL FEMUR FRACTURE WITH DISTAL FEMORAL LOCKING COMPRESSION PLATE AT KOSHI ZONAL HOSPITAL
}

\author{
Sah $S,{ }^{1 *}$ Karn NK, ${ }^{2}$ KC B, ${ }^{1}$ Yadav $R,{ }^{1}$ Dangi $S J,{ }^{3}$ Adhikari $A R^{4}$
}

\section{Affiliation}

1. Department of Orthopedics, Koshi Zonal Hospital, Biratnagar, Nepal

2. Associate Professor, Department of Orthopedics, Nobel Medical College \& Teaching Hospital, Biratnagar

3. Department of Anesthesiology, Koshi Zonal Hospital, Biratnagar, Nepal

4. Department of Physiotherapy, Koshi Zonal Hospital, Biratnagar, Nepal

\section{ARTICLE INFO}

\section{Article History}

Received : 19September, 2017

Accepted : 11 October, 2017

Published : 31 December, 2017

(C) Authors retain copyright and grant the journal right of first publication with the work simultaneously licensed under Creative Commons Attribution License CC - BY 4.0 that allows others to share the work with an acknowledgment of the work's authorship and initial publication in this journal.

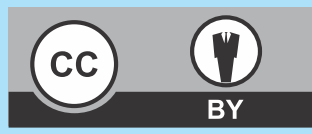

ORA 40

DOI: http://dx.doi.org/10.3126/bjhs.v2i3.18939

\section{* Corresponding Author Dr. Shambhu Sah \\ Department of Orthopedics Koshi Zonal Hospital Biratnagar, Nepal. Email:drssah@yahoo.com}

\section{Citation}

Sah S, Karn NK, KC B, Yadav R, Dangi SJ, Adhikari AR. Outcomes of Surgical Management of Distal Femur Fracture with Distal Femoral Locking Compression Plate At Koshi Zonal Hospital. BJHS 2017;2(3)4 :260-265

\section{ABSTRACT}

\section{Introduction}

Distal femoral fractures comprise 4-6\% of all femur fractures. The management of distal femur fractures are challenging because of significant morbidity and complication rate even with advanced surgical techniques and implants. Open reduction and internal fixation (ORIF) with pre-contoured distal femoral locking compression plate (DF-LCP) is one of the most acceptable surgical procedures these days.

\section{Objective}

Evaluation of functional outcomes of distal femur fractures managed surgically using DF-LCP at Koshi Zonal Hospital.

\section{Methodology}

In this cross sectional study 21 patients having closed distal femur fractures with or without intra-articular extension to femoral condyle fixed with DF-LCP at Koshi Zonal Hospital, Nepal from March 2016 to March 2017 were included. Patients with open fracture, severe comminuted fracture, and neurovascular impairment were excluded. These patients were followed-up for up to one year and we recorded the knee range of motion, full weight bearing time fracture union time, and complications. We used Neers' functional scoring system to evaluate the final outcomes and data was analysed using Microsoft Excel Programe.

\section{Results}

Out of the 21 patients of distal femur fractures, 16 were diametaphyseal distal femur fractures and five were supracondylar fractures with intra-articular extension. Mean age recorded was 45 (range 19-75) years, hospital stay mean duration 12 (range 10-19) days and duration of surgery 85 (range 60-150) minutes, full weight bearing walking time mean16 (range 12-22) weeks, radiological union time mean 20 (range 17-29) weeks and Neers' score was excellent in $66.66 \%$, satisfactory in $23.80 \%$, unsatisfactory in $4.76 \%$, and poor in $4.76 \%$. None of our patients had complications like; loss of fixation, implant failure or post-operative neurovascular injury.

\section{Conclusion}

Distal Femoral Locking Plate is one of the best implant to be used as fixation method for both extra-articular and intraarticular distal femur fracture.

\section{KEYWORDS}

Distal femur fracture; open reduction ; plate fixation 


\section{INTRODUCTION}

Distal femur fractures are uncommon but challenging injuries to treat. In older age males and females with osteoporotic bone, fractures are usually due to low energy trauma like fall from standing height or during walk. However in young patients, these fractures occurs due to high energy trauma like motor vehicle accidents, sports injuries and fall from height. ${ }^{1,2}$

Conservative management such as traction, casting or combination of both demands prolonged bed rest and can result in persistent angular deformity, bed sores and loss of knee range of motion.Surgical fixations has consistently demonstrated better outcomes than nonsurgical management. At present, early return to function is possible due to the development of new technology and newer implants for distal femoral fractures. Commonly used implants are external fixators, angled blade plates, dynamic condylar screw plates, condylar buttress plates, retrograde supracondylar inter-locking nails, Ender's nails, Rush nails etc. These implants are selected based on the fracture pattern, bone quality, functional demands and type of trauma, the condition of the patient and expertise of the surgeon. Most of these implants require C-arm fluoroscopy during operative period of fixation. Newly introduced distal femoral locking compression plate (DF-LCP) is precontoured, which provides angular stability and rigid fixation. ${ }^{3-5}$ Objective of our study is to analyses the functional outcomes of ORIF with DF-LCP in distal femur fractures.

\section{METHODOLOGY}

This cross sectional study was conducted on 21 patients admitted in orthopedic department of Koshi Zonal Hospital, Biratnagar, Nepal from March 2016 to March 2017 to analyze of the outcomes of surgical management in distal femur fractures with DF-LCP. In this study, we selected adults (skeletally mature) above 18 years and elderly with osteoporotic bone. Simple spiral, oblique, transverse and butterfly fragment with simple intra-articular extension were included but comminuted dia-metaphyseal fractures, open fractures and fractures with neurovascular injuries were excluded. We took convenient sample for this study. Ethical clearance was taken from hospital authority. No patient was harmed physically and economically for this study except their regular expenditure for treatment. Data was analyzed using Microsoft Excel Program.

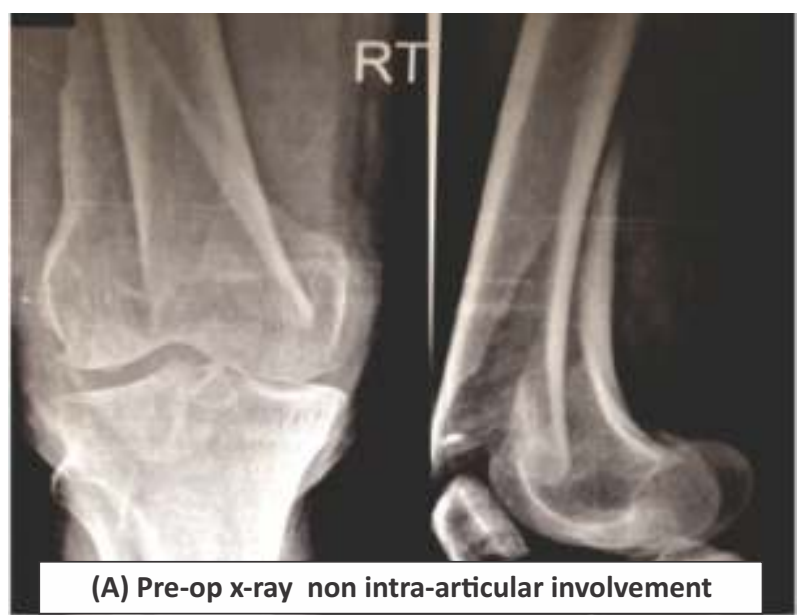

\section{PRE-OPERATIVE MANAGEMENT}

In the emergency department of Koshi Zonal Hospital, we examined thoroughly not only distal femur fracture but also carefully considered the mechanism of injury,mode of injury, associated injuries such as neurovascular injury, head injury and other system involvement. We started emergency treatment and required investigations such as X-Ray, CT scan especially in head injury or intra-articular femoral condyle fractures and other routine blood investigations. Once the patient became stable, we shifted the patient to the ward, elevated the leg on Bohler-Braun splint with non-adhesive traction. In case of delayed surgery, lower tibial skeletal traction with proper weight was applied. We prepared the patient for surgical management after pre-anesthetic checkup (PAC). Informed consents were taken for all the surgeries.

\section{SURGICALTECHNIQUE}

After pre-anesthetic checkup, all patients received regional spinal anesthesia. The patient was placed supine on a radiolucent operating table. Sand bag was placed under the ipsilateral hip, another rolled towel was placed under the knee to achieve flexed position of the knee, length and rotation was carefully controlled. We applied tourniquet in some patient depending on length of femur and extension of fracture. Routine preparation and draping of injured limb was done. Lateral incision (sub-vastus approach) was made directly on the lateral aspect of the thigh and through the midpoint of the lateral condyle distally, staying anterior to the proximal insertion of the lateral collateral ligament. The distal end of the incision was gently curved anteriorly along the lateral border of the patella upto the tibial tuberosity. Proximally incision extended as per requirement. The fascia lata was incised in line with skin incision and its fibers were split. Distally for condylar fracture exposure, it was often necessary to incise the anterior fibers of the iliotibial tract and carry down through the capsule and synovium of lateral aspect of the femoral condyle. Care was taken to identify the superior lateral genicular artery, which was ligated and to avoid damage to the lateral meniscus. ${ }^{6-8}$ Adequate exposure of articular surface, particularly, medial femoral condyle or coronal plane anatomy was managed by extension of incision as per necessity.

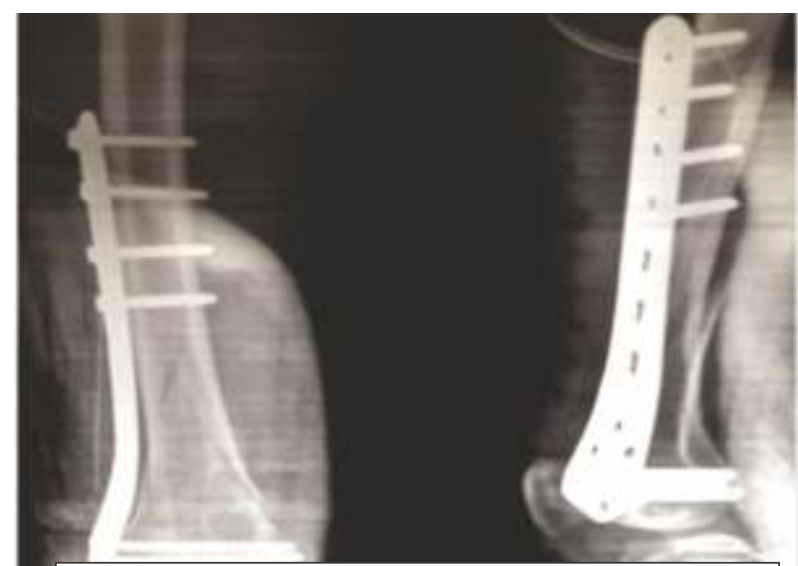

(B) Post-op x-ray non intra-articular involvement

Figure 1: Distal Femur diametaphyseal fracture (non-articular involvement) 
Vastus-lateralis muscle was reflected of lateral inter-muscular septum to expose the distal femoral shaft. Fracture reduction was achieved commonly by manual traction. For reduction of condylar fractures, we temporarily used multiple K-wires. Pre-contoured DF-LCP was placed and fixed with 3-

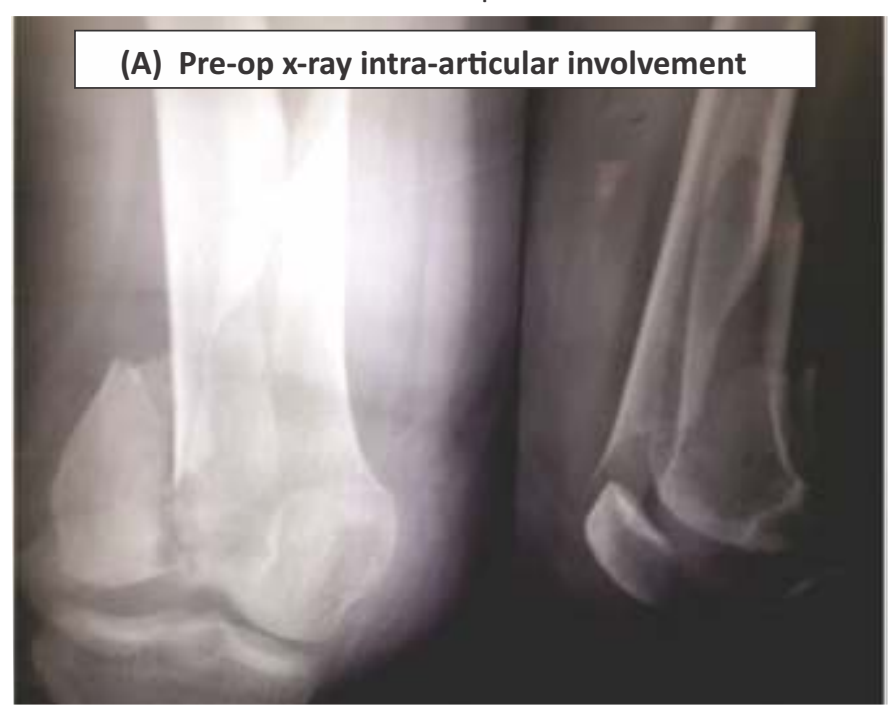

Figure 2: Distal Femur Intra-articular Extension

\section{POSTOPERATIVE PROTOCOL}

Suction drain was removed after 48-72 hours depending upon drain collection. Intravenous antibiotic was used for 5-7 days according to patient's health condition, hygiene, nutritional status, socioeconomic status, patient's habit of alcohol intake and smoking. Repeat hemoglobin was done for post-operative blood transfusion cases. Sutures removed according to wound healing condition at around $13^{\text {th }}$ day. Plaster of Paris (POP) long leg back slab was applied in every cases and removal was done depending on condition of wound healing, post-operative x-ray bone fixation, bone density,
5 cancellous locking screws distally and 3-5 cortical locking screws proximally. Hemostasis maintained and wound closure was done in layers after placement of suction drain. After dressing above knee POP slab was applied with knee at 15-20 degree flexion in intra-condylar fracture. ${ }^{9}$

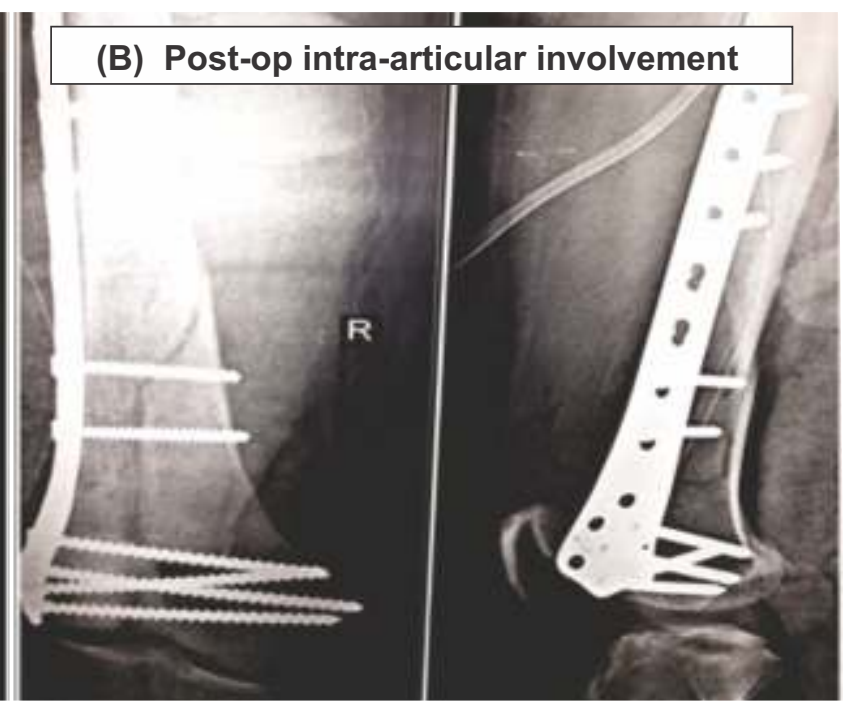

patient's behavior, and patient's hygiene maintenance. Isometric quadriceps and hamstring strengthening exercises were started after $2^{\text {nd }}$ postoperative day and active mobilization was initiated after two weeks by physiotherapist. In most of the cases, we removed POP back slab after two weeks, but in older patients, osteoporotic or intra-articular fracture slab was removed after around 3-5 weeks. Partial and full weight bearing walking was allowed on clinical and radiological evidence on follow up at 6 weeks interval. During follow up, outcomes were assessed by using Neers' functional scoring system up to six months.

Table 1 : Neers' Functional scoring. ${ }^{10,11}$

Functional ....

\section{Pain (20 units)}

5. No pain (70 Units)

4. Intermittent 20

3. With fatigue ……………........ 16

2. Restrict function .............................. 8

1-0. constant or at night . 4-0 Function (20 units)

5. As before injury ............................... 20

4. Mild restriction ................................. 16

3. Restricted, stairs sideways ............... 12

2. Cane or severe restriction.................. 8

1-0. Crutches or brace ............................ 4 4-0

Motion (20 units) Knee Flexion

5. Normal or 135 degrees ................... 20

4. 100 degrees $\quad$.............................. 16

3. 80 degrees …............................. 12

2. 60 degrees $\quad$.................................... 8

1. 40 degrees $\quad$................................ 4

0.20 degrees or less .................................. 0

Work (10 units)

5. As before injury ........................... 10

4. Regular but with handicap .............. 8

3. Alter work ................................ 6

2. Light work …........................... 4

1-0. No work
Anatomical

(30 Units)

Gross Anatomy (15 units)

5. Thickening only

4. 5 degrees angulation or $0.5 \mathrm{~cm}$ short

3. 10 degrees angulation or rotation, $2.0 \mathrm{~cm}$ short 0

2. 15 degrees angulation or rotation, $3.0 \mathrm{~cm}$ short 6

1. union but with greater deformity ............................ 3

0 . non union or chronic infection.................................. 0

Roentgenogram (15 units)

5. Near Normal 15

4. 5 degrees angulation or $0.5 \mathrm{~cm}$ displacement-

3. 10 degrees angulation or $1.0 \mathrm{~cm}$ displacement

2. 15 degrees angulation or $2.0 \mathrm{cms}$ displacement 9

1. Union but with greater deformity; spreading of condyles; osteo-arthritis..

0 . Nonunion or chronic infection.

\author{
0
}

.




\section{RESULTS}

Twenty-one patients were included in this study with average age 45 (range 19-75) years. Among them 14 were female (range 27-75) years and seven were male (range 1935 ) years. Five cases had intra-articular involvement and 16 cases were with dia-metaphyseal fracture mostly oblique and spiral. The time between injury and surgery was mean 9 (range 5-13) days. Eleven patients required blood transfusion before operative procedure and three patients got blood transfusion after surgery. All the cases were operated under spinal anesthesia. Duration of surgery was average 85 (range 60-150) minutes and average blood loss was 208 (range 150-300) $\mathrm{ml}$ without intraoperative complications. Operative duration and blood loss was more in intracondylar fractures, bulky patients and fractures with difficult reduction. All patients started isometric hamstring, gluteal and quadriceps exercises as taught by the physiotherapist on the $2^{\text {nd }}$ post-operative day and was continued till full range of movement of knee was achieved. Patients were on intravenous antibiotics after surgery for (5-7) days depending upon wound conditions which was switched to oral antibiotics till suture removal (range 12-14) days. Duration of hospital stay was average 12 (range 10-19) days. All patients were ambulated with non-weight bearing using crutches or walker after removal of sutures, except those five patients with inter-condylar fracture. Full weight bearing was allowed when the fracture union was confirmed both clinically and radiologically on average 16 (range 12-22) weeks. Inter-condylar fractures, osteoporotic bone and pain sensitive patients took longer time for full weight bearing.

Radiological union of the fracture was characterized by cortex to cortex healing and bridging callus of the fracture in both antero-posterior and lateral views of follow-up x-rays, average union time was 20 weeks (range 17-29). Neers' scorings recorded at six months post-op with the help of physiotherapists. Score assessment was excellent in $66.66 \%$, satisfactory in $23.80 \%$, unsatisfactory in $4.76 \%$ and poor in $4.76 \%$. Five patients complained of knee pain after radiological healing. Early complications were encountered in three patients, out of which two patients had developed superficial wound infection and one patient had deep infection. They were managed with intravenous antibiotic and proper dressing. None had any implant failure or any deformity.

\section{DISCUSSION}

The introduction of distal femoral locking compression plate (DF-LCP) with fixed-angle screws system offers a number of advantages in fracture fixation and DF-LCP has been rapidly adopted as an alternative to intramedullary nails, blade plates and non-locking condylar screws. Distal femur fracture reconstruction needs a very skillful hand because it's a very challenging procedures for the orthopedic surgeons. The goal of the reconstruction is not only the anatomical reduction of the articular surface but also the adequate stabilization of the fracture and early mobilization along with prevention of the stiffness and early ambulation of the patient.The prognostic factors described for distal femur fracture are age, fracture types, articular involvement, proper implant selection, timing of joint motion and surgeon's expertise. ${ }^{12-15}$ The outcomes of DF-LCP in distal femur correlated with the fracture severity, etiology, anatomic reduction, bone quality, length of time elapsed from injury to surgery, concomitant injuries and proper positioning and fixation of the implant. Any slight variation in implant placement can disturb reduction. DF-LCP is very much user-friendly technique because it makes anatomical reduction and fixation easier. It is ideal implant when the fracture of lower $1 / 3^{\text {rd }}$ femur has an intercondylar extension. ${ }^{16-18}$

Table 2: Comparison of hospital stay, operative time, weight bearing walking, radiological union ORIF with DF-LCP with other published articles

\begin{tabular}{|c|c|c|c|c|}
\hline $\begin{array}{l}\text { Previous } \\
\text { published } \\
\text { articles }\end{array}$ & $\begin{array}{l}\text { Hospital } \\
\text { stay (days) }\end{array}$ & $\begin{array}{c}\text { Operative } \\
\text { time } \\
\text { (minutes) }\end{array}$ & $\begin{array}{l}\text { Full Weight } \\
\text { bearing } \\
\text { walking (mean } \\
\text { weeks) }\end{array}$ & $\begin{array}{c}\text { Radiological } \\
\text { union(mean } \\
\text { weeks) }\end{array}$ \\
\hline Yeap EJ et al ${ }^{5}$ & $8-34$ & $80-180$ & --- & 18 \\
\hline Gupta GK. et al ${ }^{14}$ & $10-40$ & $60-90$ & 12.65 & 25.73 \\
\hline Mahesh $\mathrm{DV}^{16}$ & $20-40$ & $90-180$ & --- & 18 \\
\hline MulayS et al ${ }^{17}$ & 15 & $90-180$ & 12 & 26 \\
\hline Rao LL et $a^{18}$ & $15-25$ & --- & 13.5 & 15.7 \\
\hline Our study & $10-19$ & $60-150$ & 16 & 20 \\
\hline
\end{tabular}

Surgical fixation of distal femur fractures has consistently demonstrated better outcomes than nonsurgical management based on fixed angle devices starting with ORIF using condylar blade plate (CBP) or Dynamic Condylar Screw (DCS). However, it requires large incisions that led to increasing complication rates of infection, delayed union, non-union, iterative fractures and need for primary or secondary bone grafting. For minimizing those disadvantages, close reduction and minimal exposure to facilitate the insertion of retrograde intramedullary nail with preservation of periosteum and fracture hematoma. Newly introduced minimal invasive plate osteosynthesis (MIPO) techniques were successfully applied in complex extra-articular fractures and a modified technique entitled Transarticular Approach and Retrograde Plate Osteosynthesis (TARPO) was developed for complex supracondylar and intercondylar femoral fractures. ${ }^{19-21}$

\begin{tabular}{ccccc}
\multicolumn{4}{c}{ Table 3: Comparison of Neers' } & scores of ORIF with DF-LCP \\
\hline $\begin{array}{c}\text { Previous published } \\
\text { article }\end{array}$ & Excellent & $\begin{array}{c}\text { Satisfactory } \\
\text { (good) }\end{array}$ & $\begin{array}{c}\text { Unsatisfactory } \\
\text { (fair) }\end{array}$ & $\begin{array}{c}\text { Failure } \\
\text { (poor) }\end{array}$ \\
\hline Srinath SR et al $^{9}$ & $65 \%$ & $15 \%$ & $20 \%$ & $0 \%$ \\
\hline Krishna KR et al $^{12}$ & $50 \%$ & $36.6 \%$ & $10 \%$ & $3.3 \%$ \\
\hline Rao LL et al $^{18}$ & $32 \%$ & $48 \%$ & $16 \%$ & $4 \%$ \\
\hline Girisha BA et al $^{19}$ & $24 \%$ & $71 \%$ & $5 \%$ & $0 \%$ \\
\hline Our study & $66.6 \%$ & $23.80 \%$ & $4.76 \%$ & $4.76 \%$ \\
\hline
\end{tabular}


Since the use of plating and nailing technique has modernized, there has been a major improvement in the treatment of distal femur fractures. The revision surgery is co-related with the surgical skills of the surgeon, implant and the type of fracture. Selection of the appropriate implant depends upon the fracture pattern, the condition of the soft tissues, the need of the patient, and the preference of the surgeon.
The mean age of patients were higher, which could explain the higher mortality rate. The outcome and the prognosis of fracture depends on micro-motion and stable fixation. There are certain variables that can be controlled by surgeons and some are uncontrollable. Among the uncontrollable variables, the poor bone quality of the patient and the fracture comminution also plays a vital role. ${ }^{22-23}$

Table 4: Comparison with commonly used different implants and techniques in terms of duration of hospital stay, radiological union, blood loss, operative time and Neers' score

\begin{tabular}{|c|c|c|c|c|c|c|}
\hline $\begin{array}{l}\text { At present } \\
\text { commonly } \\
\text { used } \\
\text { techniques }\end{array}$ & Published articles & Hospital stay & $\begin{array}{c}\text { Radiological } \\
\text { Union }\end{array}$ & $\begin{array}{l}\text { Blood } \\
\text { loss }\end{array}$ & $\begin{array}{l}\text { Operative } \\
\text { time } \\
\text { (minutes) }\end{array}$ & Neers'score \\
\hline $\begin{array}{l}\text { ORIF with } \\
\text { DCS }\end{array}$ & 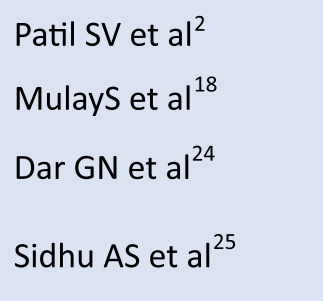 & $\begin{array}{c}18.8 \text { days } \\
17.5 \text { days } \\
\text {----- } \\
\text {----- }\end{array}$ & $\begin{array}{c}15 \text { weeks } \\
24 \text { weeks } \\
18.7 \text { weeks }\end{array}$ & $\begin{array}{c}304.2 \\
\mathrm{cc} \\
----\end{array}$ & 83.5 & $\begin{array}{l}\text { Excellent-47\% } \\
\text { Good ------ 33\% } \\
\text { Fair -------- } 17 \% \\
\text { Poor-------- } 3 \%\end{array}$ \\
\hline $\begin{array}{l}\text { Retrograde } \\
\text { interlocking } \\
\text { nail }\end{array}$ & 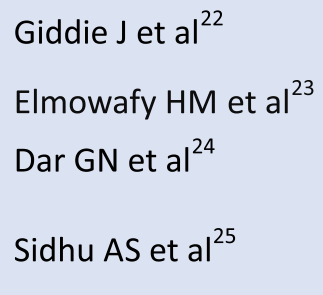 & $\begin{array}{c}14 \text { days } \\
10 \text { days } \\
\text {----- } \\
\text {----- }\end{array}$ & $\begin{array}{c}17.5 \text { weeks } \\
13 \text { weeks } \\
18.5 \text { weeks } \\
\text {---- }\end{array}$ & $\begin{array}{c}178 \\
\mathrm{cC}\end{array}$ & 102.2 & $\begin{array}{l}\text { Excellent-27\% } \\
\text { Good ----- } 46 \% \\
\text { Fair -------- } 27 \%\end{array}$ \\
\hline $\begin{array}{l}\text { MIPO with } \\
\text { DF-LCP or } \\
\text { LISS }\end{array}$ & $\begin{array}{l}\text { Nayak RM et al } \\
{ }^{23} \\
\text { Padha K et al }{ }_{27} \\
\text { Gupta SK et al }\end{array}$ & $\begin{array}{c}10 \text { days } \\
12.2 \text { days }\end{array}$ & $\begin{array}{c}14.8 \text { weeks } \\
14.2 \text { weeks } \\
18 \text { weeks }\end{array}$ & & 100.0 & $\begin{array}{l}\text { Excellent-65\% } \\
\text { Good ------ 20\% } \\
\text { Fair -------- } 10 \% \\
\text { Poor } \quad 5 \%\end{array}$ \\
\hline $\begin{array}{l}\text { ORIF with } \\
\text { DF-LCP }\end{array}$ & Our Study & 12 days & 20 weeks & $\begin{array}{c}208 \\
\mathrm{ml}\end{array}$ & 85 & $\begin{array}{l}\text { Excellent-66.6\% } \\
\text { Good--------23.8\% } \\
\text { Fair----------4.76\% } \\
\text { Poor } \quad 4.76 \%\end{array}$ \\
\hline
\end{tabular}

Technically retrograde nailing is said to be a challenging procedure due to its certain complications like; iatrogenic fracture of femoral shaft, stress fracture above the implant, fatigue failure of the nail, intra-articular impingment of the nail due to inadequate entry point, knee pain and injury to the deep femoral artery. In supracondylar fracture femur, supracondylar nailing is useful for fixation but not in case of comminuted fractures. In comparison with supracondylar nail, DCS is supposed to be a better option for management of distal end of femur fracture in terms achieving bony union with less chances of knee stiffness, knee arthrosis and better Neers' score. In supracondylar nailing group there is benefit of early weight bearing. Drawback of using plate and screws is that plate is a load shielding device and is prone refractures in osteopenic bone of the proximity of the plate. ${ }^{24-25}$
However, MIPO does not allow direct visualization of the fracture and the surgeon is dependent on intraoperative fluoroscopy for adequate reduction. The requirement for biological osteosynthesis led to the development of new generation of plates with angular stability, called Less Invasive Stabilization System (LISS). The less invasive stabilization system (LISS) is based on MIPO technique. The LCP differs from the LISS in that the LCP has combination holes and does not have a jig. The LCP acts on the principle of internal fixator and permits percutaneous plating, as locking the screws to the plate do not pull the fracture towards the implant so that the fracture does not redisplace after reduction. The LCP is compatible with MIPO.DF-LCP is a useful arsenal for orthopedic surgeons while fixing fractures around the knee especially when the fractures are severely comminuted and osteoporotic. ${ }^{26-28}$ 


\section{CONCLUSION}

The outcome of distal femoral fractures fixed with DF-LCP as shown by Neers' score is excellent with minimal complications. Hence, the DF-LCP can be used as a safe and reliable implant for both intra and extra-articular distal femur fractures to restore the length, rotation and axial alignment of the femur.

\section{RECOMMENDATIONS}

With our study results, we recommend DF-LCP can be standard method of management of distal femur fracture.

\section{LIMITATION OF THE STUDY}

Our study was single center study and had small sample

\section{REFERENCES}

1. Hoffmann MF, Jones CB, Sietsema DL, Tornetta P, Koenig SJ. Clinical outcomes of locked plating of distal femoral fractures in a retrospective cohort.Journal of orthopaedic surgery and research. 2013 Nov 27;8(1):43.

2. Patil SV, Magdum PB, Naik NP. Management of type a supracondylar fractures of femur with dynamic condylar screw (DCS). IJHBR. 2015 Jan;3(2):127-34.

3. Nagy HM, El Mehy E, Issa K. Butttress condylar plating in treatment of intercondylar supracondylar fractures of distal femur. Pan Arab J Ortho Trauma. 2007;11:26-34.

4. Batista BB, Salim R, Paccola CA, Kfuri Junior M. Internal fixators: a safe option for managing distal femur fractures? Actaorto pedicabrasileira. 2014;22(3):159-62.

5. Yeap EJ, Deepak AS. Distal femoral locking compression plate fixation in distal femoral fractures: early results. Malaysian Orthopaedic Journal. 2007;1(1):12-7.

6. Ehlinger M, Ducrot G, Adam P, Bonnomet F. Distal femur fractures. Surgical techniques and a review of the literature.Orthopaedics\& Traumatology: Surgery \& Research. 2013 May 31;99(3):353-60.

7. Link BC, Babst R. Current concepts in fractures of the distal femur. ActaChirOrthopTraumatolCech. 2012 Feb 1;79(1):11-20.

8. Albert MJ. Supracondylar fractures of the femur. Journal of the American Academy of Orthopaedic Surgeons. 1997 May 1;5(3):163-71.

9. Rao DV. Clinical Study of Locking Compression Plate Fixation in Supracondylar Fractures of Femur in Adults . Journal of International Academic Research for Multidisciplinary 2015;3(6):372-80.

10. CHARLES S NEER II, Grantham SA, Shelton ML. Supracondylar Fracture of the Adult Femur: A STUDY OF ONE HUNDRED AND TEN CASES. JBJS. 1967 Jun 1;49(4):591-613.

11. Trivedi NP, Chauhan RH, Padhiyar DR, Gandhi SP. Outcome of fracture of intra articular distal femur treated with distal femur locking compression plate. International Journal of Research in Orthopaedics. 2015 Dec 1;1(1):22-7.

12. Krishna KR, Nayak BS, Amrit G. Study of surgical management of distal femoral fractures by distal femoral locking compression plate osteosynthesis. Indian Journal of Orthopaedics Surgery. 2015;1(1):22-6.

13. Lujan TJ, Henderson CE, Madey SM, Fitzpatrick DC, Marsh JL, Bottlang M. Locked plating of distal femur fractures leads to inconsistent and asymme tric callus formation.Journal of orthopaedic trauma. 2010 Mar 1;24(3):156-62.

14. Gupta GK, Sudha Rani D, Kumar R, Singh B. Analysis of management of supracondylar femur fracture by locking compression plate. International Journal of Orthopaedics. 2016;2(4):218-22.

15. Chander A, Ganesan GR, Jayabalan V. Is Distal Femur Locking Plate a Superior Implant in Distal Femur Fracture?. Open Journal of Orthopedics. $2015 \operatorname{Sep}$ 1;5(09):258. size. Hence, we recommend a larger sample size and multicentric study with longer follow up.

\section{ACKNOWLEDGMENT}

Grateful to Dr. Roshan Pokhrel (Medical Superintendent), Dr. Mukund Dahal (HOD, Ortho-Department) and Mrs. Anjula Karki (OT-Incharge) from Koshi Zonal Hospital for supporting in this study.

\section{CONFLICT OF INTEREST}

The authors declare no financial support or conflict of interest.

16. Mahesh DV, Gunnaiah V. Management of Distal Femur Fracture by Locking Compression Plate. International Journal of Health Sciences and Research (IJHSR). 2014;4(5):235-40.

17. Mulay S, Patel M, Gandhi D, Suri N. Comparative study of fracture lower $1 / 3$ rd femur fixed by dynamic condylar screw and locking condylar plate. International J. of Healthcare and Biomedical Research. 2016 Apr;4(03):98-102.

18. Rao LL, Kumar TD, Paleti ST, et al. Evaluation of functional outcome after open reduction and internal fixation of distal femur fractures by locking compression plate. J. Evid. Based Med. Healthc. 2016; 3(73), 3966-3972.

19. Girisha BA, Manchani S, Shah R, Muralidhar N. Outcome of distal femoral fractures treated with locking compression plates. International Journal of Research in Orthopaedics.2017 Jun 7.

20. Sîrbu PD, Asaftei R, Petreus T, Lupascu C, Puha B, Lunca S. Transarticular approach and retrograde plate osteosynthesis (TARPO) using implants with angular stability-A series of 17 cases of complex distal femoral fractures type C3/AO. Chirurgia (Bucur). 2014;109(2):233-7.

21. Nayak RM, Koichade RM, Umre AN, Ingle MV. Minimally invasive plate osteosynthesis using a locking compression plate for distal femoral fractures. Journal of orthopaedic surgery. 2011 Aug; 19(2):185-90.

22. Giddie J, Sawalha S, Parker M. Retrograde nailing for distal femur fractures in the elderly. SICOT-J. 2015;1.

23. Elmowafy HM, Hassan BZ, Nassar AM. Role of retrograde short nail in the treatment of supracondylar femoral fractures (extra-articular type A). Menoufia Medical Journal. 2015 Jan 1;28(1):142.

24. Gh Nabi DA, Shafaat Rashid TA, Khursheed Ahmed KANGOO MA. Bridge plate osteosynthesis using dynamic condylar screw (DCS) or retrograde intramedullary supracondylar nail (RIMSN) in the treatment of distal femoral fractures: comparison of two methods in a prospective randomized study. Turkish Journal of Trauma \& Emergency Surgery. 2009;15(2):148-53.

25. Sidhu AS, Mann HS, Sidhu GD, Bassi A, Banga A. Management of distal fracture femur-Supracondylar nailing versus open dynamic condylar screw. Pb J Orthopaedics. 2011;12(1):22-6.

26. Walia JP, Malu G, Walia SK, Gupta AC, Sethi S, Singh S. Minimally Invasive Plate Osteosynthesis for Distal Femoral Fractures.JIMSA 2014;27(4):197-198.

27. Padha K, Singh S, Ghani A, Dang H. Distal Femur Fractures and its Treatment with Distal Femur Locking Plate.JK SCIENCE 2016;18 (2):76-80.

28. Gupta SV, Dande R. Surgical management of fracture of distal end of femur in adults by minimal invasive percutaneous plate osteosynthesis (MIPPO) with locking condylar plate. International Journal of Orthopaedics. 2015;1(2):07-11. 